\title{
Understanding public attitudes towards partial restoration of the Ocklawaha River
}

\author{
Natalie Sabine Hollander \\ University of Florida
}

Faculty mentor: Xiang Bi, Food and Resource Economics Department (FRED)

\begin{abstract}
The Ocklawaha River was dammed in 1968 to accommodate the construction of the Cross Florida Barge Canal. The resulting Kirkpatrick Dam formed a reservoir that changed the historical riverine and floodplain ecosystems of the Ocklawaha river. The damming resulted in negative impacts to native fish and plant species within the reservoir and river, in addition to poor water quality upstream. However, the resulting large reservoir became a favored location for centralized bass fishing. While the debate between recreationists and environmentalists on the correct course of action in regard to breaching the Kirkpatrick Dam has been ongoing for five decades, there are many skewed public perceptions in comparison to what is scientifically true. This paper analyzes trends between the survey participants' demographics and their held opinion on breaching the Kirkpatrick Dam to partially restore the Ocklawaha River and the surrounding floodplain. The popularity of individuals holding false perceptions on the Ocklawaha River restoration highlights the need for more scientific education and outreach programs to assist in reducing these misconceptions and uncertainty on the future of the Ocklawaha River.
\end{abstract}

\section{Introduction}

In March of 1966, Florida state officials formally endorsed damming the Ocklawaha in relation to the construction of the Cross Florida Barge Canal (Godfrey and Catton, 2012), a canal project to connect the Gulf of Mexico and the Atlantic Ocean across Florida as a direct shipping route in an effort to boost economic development within Florida (FDEP, 1995; Borisova et al., 2017a). This barge canal was planned to go from Jacksonville to Yankeetown, which would modify the St. Johns, Ocklawaha, and Withlacoochee Rivers through a resulting approximately 177-kilometer-long channel across the state of Florida that would cover nearly 31,161 hectares (FDEP, 1995). After this endorsement, the Army Corps of Engineers continued construction on the Rodman Reservoir and the Rodman Dam (Godfrey and Catton, 2012).

In 1971, President Nixon ordered the Army Corps of Engineers to cease working on the canal as several ecological studies concluded that this canal would significantly harm the surrounding environment, in addition to the project being economically unjustified (Godfrey and Catton, 2012). Before the construction was halted in 1971, one-third of the canal's construction was already completed (Harms et al., 1980), which included the Rodman Dam, later renamed the 
George Kirkpatrick Dam, which is 6.7 meters high and 2,073 thousand meters long (Shuman, 1995). The Kirkpatrick Dam has never been used for hydropower generation, navigation, or water storage purposes (Bi et al., 2019). Recreation is the primary use of the Rodman Reservoir, such as bass fishing, canoeing, kayaking, site-seeing, and wildlife viewing opportunities (Bi et al., 2019). The Cross Florida Barge Canal was officially de-authorized in 1991 (Borisova et al., 2017b), resulting in the 177-kilometers of land originally set aside for the canal construction to become the Marjorie Harris Carr Cross Florida Greenway in 1998 (Noll \& Tegeder, 2009).

Although the Cross Florida Barge Canal was never completed, the damage from the Kirkpatrick Dam resulted in multiple negative ecosystem effects to the surrounding area. The dam created an artificial lake that flooded and destroyed 3,885 hectares of the Ocklawaha river and its floodplain forest (FDEP, 1995). This resulted in the loss of habitat connections between the river and the floodplain forest (USDA FS, 2001), as well as flooding 1,620 hectares of surrounding upland forests (Harms et al., 1980). In addition, the dam limited the upstream passage of certain aquatic animals, resulting in decreased fish diversity. The dam acts as a barrier to certain aquatic and fish species that have historically migrated upstream, such as channel catfish, striped bass, and manatees (Borisova et al., 2017a). The reduction in fish species is also predicted to be a result of the change in habitat from a flowing river to a standing reservoir (USDA FS, 2001). Additionally, the dam has affected sediment movement, discharge volumes, and the natural flow to the downstream portions of the Ocklawaha River (Shuman, 1995; Lewis, 2015), as well as alterations in nutrient exchanges (USDA FS, 2001).

Due to the negative impacts on the historical ecosystem and the new recreational opportunities that the reservoir has brought, there is controversy over what the correct course of action is (Noll and Tegeder, 2009). There is debate over whether the dam should be breached, allowing the Ocklawaha river and its surrounding floodplain to be restored to its original state, or if the reservoir should remain due to centralized bass fishing. Typically, Ocklawaha visitors that are engaged in fishing and boating within the reservoir want the dam to remain intact. In contrast, many environmentalists argue for the river and the surrounding floodplain to be restored to its natural habitat through breaching or removing the dam (Noll and Tegeder, 2009).

Partial restoration of the Ocklawaha River was recommended by an Environmental Impact Statement that was conducted by the U.S. Department of Agriculture and the Florida Department of Environmental Protection, as this would involve the minimal efforts necessary to 
restore the functions of the Ocklawaha River and its surrounding floodplain to preconstruction conditions (USDA, 2001). Partial restoration includes the partial removal of the Kirkpatrick dam, reconnecting the historical river channel above and below the dam, and restoring the Ocklawaha Rivers' floodplain hydrology (USDA, 2001).

\section{Research Objectives}

These differences in views of the Kirkpatrick Dam and the Ocklawaha River are the focus of this paper. While these opposing opinions are well known, the trends and correlations between the two opposing groups, environmentalists and recreationalists, in regard to their demographics and their opinions concerning the Ocklawaha River, Rodman Reservoir, and surrounding ecosystem need more study. Studying population demographics in relation to opinions held on breaching the dam and restoring the floodplain or leaving it intact can allow a better understanding as to why individuals hold certain perceptions, including potential misunderstandings. This will inform water resource managers and policy makers how to design better targeted education and outreach programs. Therefore, the objective of this research is:

a. To examine the extent to which residents' perception on the economic and ecological impacts of the dam affect their attitudes on partial dam removal

b. To examine the extent to which providing information on the restoration process changes residents' attitudes on partial dam removal.

\section{Survey Design and Data Collection}

A 45-item online survey was developed and administered to an online survey panel managed via Qualtrics in June and July 2018. 548 completed survey responses were obtained, with each participant receiving a payment of about $\$ 3$. Screening questions were included to ensure respondents were representative of Florida's adult population in terms of sex, race, household income, and age distribution. The online survey included items specifically designed to educate participants about restoring the Ocklawaha River through the partial removal of Kirkpatrick Dam. The survey used was approved by the Internal Review Board at the University of Florida with the IRB number IRB201801140 to ensure the language and phrasing used did not lead to a biased survey. 


\section{Sample Summary Statistics}

When compared to the U.S. Census Bureau's estimated 2018 demographics for the state of Florida, the sample represents Florida's population in terms of sex, race, and household income, with variances in education attainment (Table 1). The demographics of reported females within our conducted survey correlate to the same percentage that is reported in the U.S. Census of Florida, which is $51.1 \%$. Based on the Census, the composition of the Florida population is 54.1\% White, 25.6\% Hispanic, and 16.9\% Black or African American. In the survey sample, the composition of the respondent population is $56.6 \%$ White, $25.4 \%$ Hispanic, and $16.8 \%$ Black or African American. Education attainment varied, with $99.8 \%$ of the survey respondents graduating high school or beyond, including $48.9 \%$ obtaining a Bachelor's degree or higher, compared to the U.S. Census of Florida reporting $87.6 \%$ of Florida's population graduating either high school or beyond, including $28.5 \%$ obtaining a Bachelor's degree or higher. In addition, Florida's median household income is $\$ 50,883$ (U.S. Census Bureau, n.d.). Therefore, survey respondents were separated into two groups of reported household income: above $\$ 50,000$ or below $\$ 50,000$. The distribution of household income reported in the survey sample was similar to Florida's population, with the U.S. Census of Florida reported $49.2 \%$ having a household income below $\$ 50,000$ and 50.9\% reported a household income above $\$ 50,000$, while $46.7 \%$ of our survey participants reported a household income below $\$ 50,000$ and $50.0 \%$ reported a household income above $\$ 50,000.3 .3 \%$ of survey participants declined to provide their household income.

Table 1. Table of Survey Participants' Demographics

Demographic Categories

\section{Performed Survey Percentage}

$(\mathrm{N}=548)$

Gender

\begin{tabular}{ccc}
\hline Female & $51.1 \%$ & $51.1 \%$ \\
\hline Ethnicity & & $54.1 \%$ \\
White & $56.6 \%$ & $16.9 \%$ \\
Black or African American & $16.8 \%$ & $25.6 \%$ \\
Hispanic & $25.4 \%$ & $3 \% *$ \\
Asian or Pacific Islander & $0.9 \%$ & $\mathrm{~N} / \mathrm{A}$ \\
Other & $0.3 \% * *$ & $87.6 \%$ \\
\hline Education & & $28.5 \%$ \\
\hline High school graduate or higher & $99.8 \%$ & \\
Bachelor's degree or higher & $48.9 \%$ & $49.2 \% * * *$
\end{tabular}


Above 50,000

$50.0 \%$

$50.9 \% * * *$

*United States Census Bureau separated Asian or Pacific Islander into two separate categories that were added together for comparison purposes. The original two categories were "Asian alone", which was $2.9 \%$, and "Native Hawaiian and Other Pacific Islander alone", which was $0.1 \%$.

**Survey respondents who selected "Other" had the option of inputting a different ethnicity than those which were offered

*** Household income for Florida's population was obtained from American FactFinder, where the reported number of participants who provided their income was 7,510,882

The survey elicited respondent's attitudes on whether the natural flow of the Ocklawaha River should be restored through breaching the existing Kirkpatrick Dam. Respondents were first asked if they are familiar with the Ocklawaha River and Kirkpatrick Dam and the issues concerning it. Respondents were then presented with the history of the Kirkpatrick Dam and its impact on the river-based ecosystem, followed by an attitudinal question. Figure 1 and Figure 2, which were both shown to the survey participants, present the historical landscape before the dam and the current status of the river, dam, and part of the reservoir.

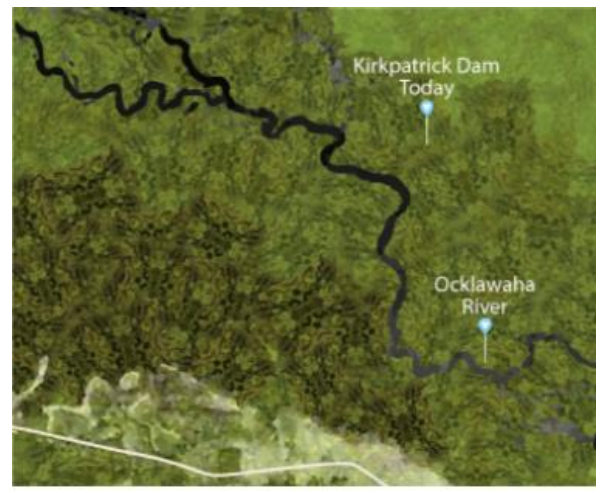

Figure 1. Historical landscape of the Ocklawaha River prior to the Kirkpatrick Dam

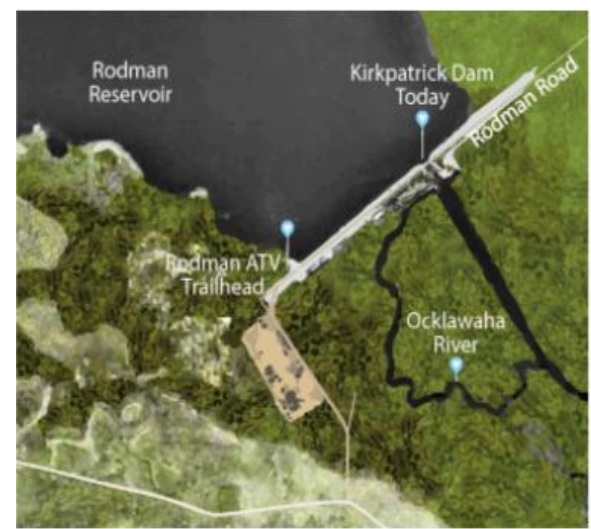

Figure 2. Current status of the Ocklawaha River, Kirkpatrick Dam, and Rodman Reservoir 
Next, respondents were presented with a description of the proposed partial restoration plan to depict the process of partially restoring the flow, hydrology, and floodplain of the Ocklawaha River. This plan involves removing a small section of the dam and connecting the historical river channel below and above the dam. Information was also presented about the potential impacts the plan would have on the reservoir, including the gradual drawn down of to the current water level, the reservoir being reduced from 3,642-4,047 hectares to 809-1,214 hectares, and the current boat ramps at the reservoir recreation areas being maintained after the partial restoration. Figure 3 and Figure 4, which were both shown to the survey participant, present the visual representation of the restoration process.

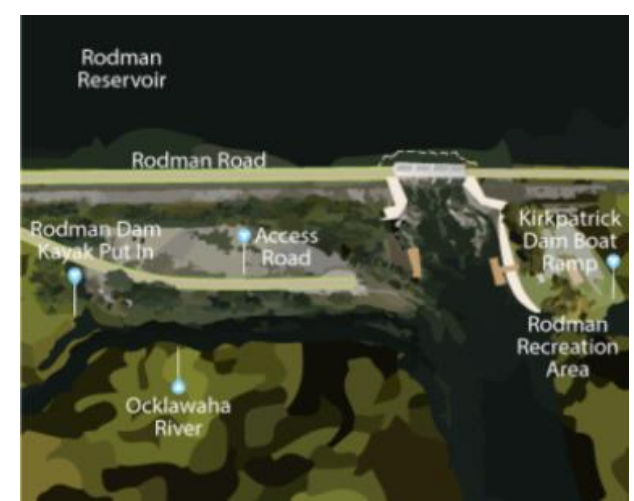

Figure 3. The current status of the Ocklawaha River, Kirkpatrick Dam, and Rodman Reservoir

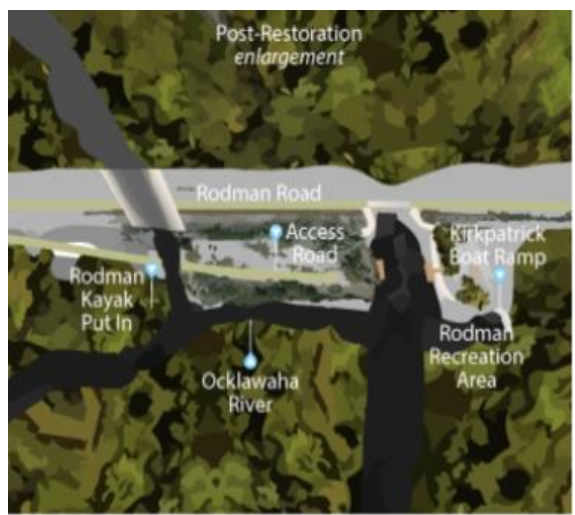

Figure 4. The status of the Ocklawaha River, Kirkpatrick Dam, and Rodman Reservoir after the partial restoration process

Following the information on the proposed partial restoration plan, the attitudinal question was asked again. Table 2 summarizes the responses before and after the partial restoration plan was presented. 
Table 2. Survey respondents' responses to breaching the Kirkpatrick Dam

\begin{tabular}{ll}
\hline Survey Respondents Answer Selection & Percentage Answered \\
\hline Before Partial Restoration Plan & \\
\hline Yes, breach the dam and restore the Ocklawaha River & $50.2 \%$ \\
& $20.8 \%$ \\
No, leave it as is & $29.0 \%$ \\
& \\
Not sure & $59.1 \%$ \\
\hline After Partial Restoration Plan & $19.9 \%$ \\
\hline Breach the dam and restore the Ocklawaha River & $21.0 \%$ \\
Leave it as is & \\
Not sure & \\
\hline
\end{tabular}

After being given more knowledge of the topic, which was provided in the latter attitudinal question, the answer choice, "Breach the dam and restore the Ocklawaha River", increased by $8.9 \%$, while, "Leave it as is", decreased by $0.9 \%$, and the answer choice, "Not sure", decreased by $8.0 \%$. The initial attitudes of those who wanted the dam to be breached and the initial attitudes of those who did not want to dam to be breached stayed nearly the same after the information on the partial restoration plan was presented, likely because the information mainly informed those who selected the "Not sure" answer choice to choose one of the other two answer selections.

\section{Statement Analysis}

In an attempt to understand the public's opinion on the damming of the Ocklawaha River, the survey respondents were asked to rank nine statements on a five-point Likert scale (strongly agree, somewhat agree, neither disagree or agree, somewhat disagree, and strongly disagree) after the partial restoration plan was presented. Table 3 presents the survey respondent's perceptions on each of the statements, with the percentage indicating the respondents who agreed (strongly and somewhat agree) with the statement. 
Table 3. Percentage of survey respondents who agree (strongly and somewhat agree) to the statement shown

\section{Statement Number}

\section{Statement Presented}

Percentage of Survey

Respondents Who Agreed

\begin{tabular}{|c|c|c|}
\hline 1 & $\begin{array}{l}\text { Maintaining the dam, locks, and } \\
\text { the reservoir is costly at the } \\
\text { taxpayer's expense. }\end{array}$ & $57.8 \%$ \\
\hline 2 & $\begin{array}{l}\text { Breaching the dam and restoring } \\
\text { the river will help the local } \\
\text { economy. }\end{array}$ & $51.1 \%$ \\
\hline 3 & $\begin{array}{l}\text { Breaching the dam will improve } \\
\text { the passage of manatees and } \\
\text { migratory fish. }\end{array}$ & $62.0 \%$ \\
\hline 4 & $\begin{array}{l}\text { Breaching the dam will improve } \\
\text { water quality in the Ocklawaha and } \\
\text { St. Johns Rivers. }\end{array}$ & $61.5 \%$ \\
\hline 5 & $\begin{array}{l}\text { Breaching the dam will enhance } \\
\text { nature-based recreation. }\end{array}$ & $63.0 \%$ \\
\hline 6 & $\begin{array}{l}\text { Breaching the dam will hurt the } \\
\text { local economy. }\end{array}$ & $23.7 \%$ \\
\hline 7 & $\begin{array}{l}\text { Breaching the dam is costly at the } \\
\text { tax payer's expense. }\end{array}$ & $51.6 \%$ \\
\hline 8 & $\begin{array}{l}\text { Restoring the river will reduce } \\
\text { bass fishing opportunities. }\end{array}$ & $43.4 \%$ \\
\hline 9 & $\begin{array}{l}\text { Maintaining the reservoir will } \\
\text { help ensure plenty of water supply to } \\
\text { the region in the future. }\end{array}$ & $54.2 \%$ \\
\hline
\end{tabular}

A percentage of survey respondents agreed with statements that have been shown to be accurate according to reported data. In Statement 1, 57.8\% of respondents agreed that maintaining the dam, locks, and the reservoir is costly at the taxpayers' expense. This is true since the cost of repairs to the Kirkpatrick Dam and Spillway was estimated to be $\$ 320,000$ (FDEP, 2015). In Statement 3, 62\% of survey respondents agreed that breaching the dam will improve the passage of manatees and migratory fish. If the Ocklawaha River is partially restored and the floodplain acreage is increased, it is expected to lead to manatees and migratory fish, such as the striped bass and mullet, to return to the river, as these species are forced to use the Buckman Lock as a portal from the St. Johns River to the Rodman Reservoir and the upper Ocklawaha River (USDA FS, 2001). The Buckman Lock currently increases the risk of manatee and fish death or injury due to the vessel and water control structures striking them, therefore, restoration efforts would allow the manatees and migratory fish to access the rest of the Ocklawaha River safely (USDA FS, 2001). Additionally, the decrease in freshwater fish species within the river is likely due to the change from a flowing river system to a standing reservoir 
(USDA FS, 2001). In Statement 8, 43.4\% of survey respondents agreed that restoring the river will reduce bass fishing opportunities. Sport fisheries production will likely decrease the density of fish per area with partial restoration (USDA FS, 2001). In Statement 4, 61.5\% of survey respondents agreed that breaching the dam will improve water quality in the Ocklawaha and St. Johns Rivers. Currently, the Rodman Reservoir is hypereutrophic due to contained nutrients, such as phosphorus and nitrogen, from the limited amount of flushing and trapped upstream nutrients in plant biomass and sediment due to the dam (USDA FS, 2001). If the reservoir was removed, the contained nutrients would be able to flow downstream to improve the water quality, allowing for more suitable conditions for aquatic plants and animals (USDA FS, 2001). In Statement 5, 63.0\% of survey participants agreed that breaching the dam will enhance naturebased recreation. There would be an increase in opportunities for nature-based recreation, such as hunting, camping, hiking, and fishing (USDA FS, 2001).

There are many misconceptions that some of the survey respondents also agreed with. In Statement 6, 23.7\% of survey respondents agreed that breaching the dam will hurt the local economy. The economic impact of annual visitor spending for recreation at the Rodman Reservoir adds a total of $\$ 13,269,755$ to the gross domestic product (GDP) of Putnam, Alachua, and Marion counties combined (Borisova et al., 2017a). When compared to the combined 2017 GDP of these counties, this is only $0.058 \%$ of their overall GDP (U.S. Bureau of Economic Analysis, 2018). This also proves a misconception of the $51.1 \%$ of survey respondents who agreed with Statement 2, that breaching the dam and restoring the river would benefit the local economy, as the reservoir is not a large portion of the surrounding areas economy. However, breaching the dam and restoring the river would result in the taxpayers not contributing to maintenance costs for the dam and reservoir. In Statement 7, 51.6\% of survey participants agreed that breaching the dam is costly at the taxpayers' expense. The partial restoration is estimated to be \$7-\$14 million dollars over the course of ten years under partial restoration (FDEP, 1995). While this may seem to be a large number, $\$ 270,000-\$ 333,000$ worth of operational costs have been spent annually since 1993-1995 (USDA FS, 2001). If these expenses have been consistent from 1993 to 2018 , an estimated of $\$ 6.8-\$ 8.3$ million has already been paid to keep the dam in operation. This total cost of operation will continue to increase unless some form of restoration and dam removal is implemented. In Statement 9, 54.2\% of survey respondents agreed that maintaining the reservoir will help ensure plenty of water supply to the region in the future. The 
impounded water in the Rodman Reservoir only provides recreation and fishing opportunities, not potable water supply (USDA, 2001).

\section{Logistical Regression}

In order to better determine how the population feels about the Ocklawaha River, the Kirkpatrick Dam, and Rodman Reservoir in relation to demographics, multiple logistic regressions were performed with participants' demographics and their level of agreement (strongly and somewhat agree equals 1; neither agree nor disagree, somewhat disagree, and strongly disagree equals zero) to the statements listed in Table 3 to the dependent variable on whether they selected to breach the dam or leave it as is. Statements 1-5 from Table 3 are grouped together as perceived benefits of breaching the dam and restoring the river. It is expected that the survey respondents who agreed with one of these statements will likely support breaching the dam (Table 4). Statements 6-9 from Table 3 are grouped together as perceived costs of breaching the dam and restoring the river. It is expected that the survey respondents who agreed with one of these statements will likely prefer to keep the dam intact (Table 5). The number of observations was reduced from 548 to 530 as eighteen survey participants refused to provide household income information.

Table 4. Logistical regression for statements 1-5 listed in Table 3 with respect to perceptions on breaching the dam after being shown the partial restoration plan

\begin{tabular}{ccc}
\hline Variables & Odds Ratio & Standard error \\
\hline Gender (male) & 1.02 & 0.19 \\
Race (white) & 1.34 & 0.25 \\
Household income above & 1.10 & 0.20 \\
50k & & \\
Education attainment & 0.97 & 0.23 \\
above high school & $1.44 * * *$ & 0.19 \\
Statement 1 & 1.02 & 0.17 \\
Statement 2 & $1.82 * * *$ & 0.33 \\
Statement 3 & 0.81 & 0.15 \\
Statement 4 & 0.78 & 0.15 \\
Statement 5 & 0.66 & 0.19 \\
Constant & & \\
\hline
\end{tabular}

$\mathrm{N}=530$; Loglikelihood= -354.94; Pseudo R-squared=0.034; *** $\mathrm{p}<0.01, * * \mathrm{p}<0.05, * \mathrm{p}<0.10$ 
Table 5. Logistical regression on statements 6-9 listed in Table 3 with respect to perceptions on breaching the dam after being shown the partial restoration plan

\begin{tabular}{ccc}
\hline Variables & Odds Ratio & Standard error \\
\hline Gender (male) & 1.02 & 0.19 \\
Race (white) & 1.43 & 0.26 \\
Household income above & 1.10 & 0.19 \\
50k & & \\
Education attainment & 1.07 & 0.25 \\
above high school & & \\
Statement 6 & 1.14 & 0.15 \\
Statement 7 & 1.10 & 0.14 \\
Statement 8 & 1.00 & 0.13 \\
Statement 9 & 0.98 & 0.13 \\
Constant & 0.74 & 0.20 \\
\hline likelihood= -364.05; Pseudo R-squared $=0.009 ; * * \mathrm{p}<0.01, * * \mathrm{p}<0.05, * \mathrm{p}<0.10$
\end{tabular}

In Table 4, the results suggest that participants who supported breaching the dam are mainly motivated by concerns on dam operation and maintenance cost (Statement 1 in Table 3), and the passage of manatees and other migratory fish (Statement 3 in Table 3). For the purpose of interpretation, estimated odds ratio were reported from the logistic regression instead of coefficients. The odds ratio for Statement 1 indicates that the odds of supporting breaching the dam will increase by an exponent of 1.44 , or increase by $44 \%$, if the respondent agrees that maintaining the dam is costly, compared to respondents who disagree with the statement. In addition, the odds ratio for Statement 3 indicates that the odds of supporting breaching the dam will increase by an exponent of 1.82 , or increase by $82 \%$, if the respondent agrees that breaching the dam will improve the passage of manatees and migratory fish, compared to respondents who disagree with the statement. Regarding Table 5, there were no odds ratios that were statistically significant in relation to participants supporting breaching the dam and the statements presented. In addition, data demonstrated that demographics such as household income, education, and gender, do not significantly affect the opinion to keep or breach the dam.

\section{Conclusions}

After controlling for demographics, the data results indicated that allowing passage of manatees and migratory fish and concerns for the cost of dam maintenance are the major drivers 
influencing participant's support for breaching the dam. There are certain misconceptions about the current state of the dam and reservoir, in addition to misconceptions on breaching the dam. Such statements include Statement 2, 6, 7, and 9, however, the logistical regressions in Table 4 and Table 5 found that they are not significantly affecting opinions to breach the dam.

Managing water resources under the historically distorted conditions is challenging. Providing scientific evidence and design education and outreach programs may reduce misconceptions and reduce residents' uncertainty on the future of the Ocklawaha River. Future discussions on the Ocklawaha River should involve scientific knowledge, updated benefits and cost analysis, and potential migration strategy for negatively affected local communities rather than perceptions and ideology alone.

\section{References}

Bi, X., Borisova, T., \& Hodges, A. W. (2019). Economic Value of Visitation to Free-Flowing and Impounded Portions of the Ocklawaha River in Florida: Implications for Management of River Flow. The Review of Regional Studies, 49, 244-267.

Borisova, T., Bi, X., Hodges, A., \& Holland, S. (2017a). Is the tide is changing? Assessing costs and benefits of dam removal and river restoration: a case study in Florida. 2017 Annual Meeting, February 4-7, 2017, Mobile, Alabama 252833, Southern Agricultural Economics Association.

Borisova, T., Bi, X., Hodges, A., \& Holland, S. (2017b). Economic Importance and Public Preferences for Water Resource Management of the Ocklawaha River. University of Florida.

Florida Department of Environmental Protection (FDEP). (1995). A socio-economic study of the Rodman Reservoir. Tallahassee, FL: Florida Department of Environmental Protection, Economic Analysis Section, Office of General Counsel

Florida Department of Environmental Protection (FDEP). (2015). Kirkpatrick Dam and Spillway Condition Assessment.

Godfrey, M. C., \& Catton, T. (2012). River of Interests: Water Management in South Florida and the Everglades, 1948-2010. Historical Research Associates, Inc.

Harms, W. R., Schreuder, H. T., Hook, D. D., \& Brown, C. L. (1980). The Effects of Flooding on the Swamp Forest in Lake Ocklawaha, Florida. Ecology,61(6), 1412-1421. doi:10.2307/1939050 
Lewis, R. R. (2015). Management and restoration of the fish populations of Silver Springs and the Middle and Lower Ocklawaha River, Florida, USA. A report prepared for the Putnam County Environmental Council. Revised Version 1.

Noll, S., \& Tegeder, D. (2009). Ditch of Dreams: The Cross Florida Barge Canal and the Struggle for Florida's Future. University Press of Florida.

Shuman, J.R. (1995). Environmental Considerations for Assessing Dam Removal Alternatives for River Restoration. Related Rivers: Research \& Management, 11: 249-261. doi:10.1002/rrr.3450110302

U.S. Bureau of Economic Analysis. (2018). Local Area Gross Domestic Product 2018. Retrieved from https://www.bea.gov/system/files/2019-12/lagdp1219.pdf

U.S. Census Bureau. (2017). American FactFinder. Retrieved from https://factfinder.census.gov/faces/nav/jsf/pages/index.xhtml

U.S. Census Bureau. (n.d.). QuickFacts: Florida. Retrieved from https://www.census.gov/quickfacts/fl

U.S. Department of Agriculture Forest Service (USDA FS). (2001). Draft Environmental Impact Statement for the Ocklawaha River Restoration Project. Management Bulletin R8-MB 88. U.S. Department of Agriculture, Forest Service Southern Region. 